\title{
Global patterns of community assembly on coral reefs
}

Julie Vercelloni ${ }^{1}$, Chris Brown ${ }^{2}$, Kristen Brown ${ }^{3}$, Dominic Bryant ${ }^{3}$, M. Julian Caley ${ }^{1}$, Carolina Castro-Sanguino ${ }^{3}$, Anjani Ganase ${ }^{4}$, Manuel Gonzalez-Rivero ${ }^{3}$, Emma Kennedy ${ }^{3}$, Catherine $\mathrm{Kim}^{3}$, Sebastian Lopez-Marcano ${ }^{3}$, Kerrie Mengersen ${ }^{1}$, Camilo Mora ${ }^{5}$, Alan Pearse $^{1}$, Erin Peterson ${ }^{1}$, Marji Puotinen ${ }^{6}$, Veronica Radice ${ }^{3}$, Alberto Rodriguez-Ramirez ${ }^{3}$, and Ove Hoegh-Guldberg 7,8

${ }^{1}$ Queensland University of Technology

${ }^{2}$ Griffith University

${ }^{3}$ The University of Queensland

${ }^{4}$ Florida Institute of Technology

${ }^{5}$ University of Hawaii

${ }^{6}$ Australian Institute of Marine Science

${ }^{7}$ University of Queensland

${ }^{8}$ University fo Queensland

May 5, 2020

\begin{abstract}
The structure of coral reef communities results from interacting evolutionary, ecological and environmental forces. How these factors interact in structuring these communities at a global scale, and how such effects might vary among biogeographical regions is unclear. We partitioned sources of reef community assemblage patterns by environmental, latent (i.e. unobserved), and random factors on 291 coral reefs distributed across five biogeographical regions. We then estimated how these factors were related to variations in abundance and co-occurrence among 16 functional groups. Latent factors better explained the distributions of opportunistic functional groups like algae, whereas environmental factors better explained abundance and cooccurrence of hard corals. Co-occurrence patterns revealed complex interactions between coral and algae groups that were not related to environmental factors but influenced by regional biogeography. Our results show that environmental factors are not the sole drivers of coral reef structure highlighting the importance of assemblage-level interactions and unobserved variables.
\end{abstract}

\section{Hosted file}

Vercellonietal_Global.pdf available at https://authorea.com/users/301309/articles/431111global-patterns-of-community-assembly-on-coral-reefs 